\title{
Bridges Jyväskylä 2016
}

\author{
Paul Gailiunas ${ }^{1}$ iD
}

Published online: 20 December 2016

(C) Kim Williams Books, Turin 2016

\begin{abstract}
The 2016 edition of the annual Bridges conference for mathematics and the arts took place 9-13 August 2017 in Jyväskylä, Finland.
\end{abstract}

Keywords Bridges · Reza Sarhangi · Mathematics and art

The nineteenth Bridges conference took place in 2016 in the University of Jyväskylä, Finland. Jyväskylä is a rapidly growing city in the centre of the country. Alvar Aalto set up his first architectural practice in Jyväskylä, and some of the buildings in the city and university, including the Alvar Aalto Museum, which was included in the conference excursion, were designed by him.

Bridges has been held annually since 1998. It began in a small way in Winfield, Kansas, and remained there until 2003, when the first conference outside the US was held in Granada, Spain. Since then it has grown to become the leading international interdisciplinary conference on links between mathematics and all of the arts, including two-dimensional art, sculpture, architecture, music, poetry, drama, film, and computer science.

From its earliest days education has been an important component, with an additional "teachers' day" (scheduled after the conference) in the first few years, which later grew and was incorporated into the main conference as workshop sessions parallel to regular and short paper talks. This year education had even greater prominence with plenary talks devoted to some of the interdisciplinary research into teaching and learning mathematics that is being carried out at the University of Jyväskylä.

Paul Gailiunas

paulgailiunas@yahoo.co.uk

125 Hedley Terrace, Gosforth, Newcastle NE3 1DP, UK 
No reviewer could hope to give a comprehensive account of a conference such as Bridges, with many parallel sessions, additional events and an extensive and varied art exhibition. The Bridges website (http://www.bridgesmathart.org), which includes all of the printed proceedings in the Bridges Archive and the art exhibits in the Galleries, provides a more comprehensive view. One of the plenary sessions this year was Henry Segerman's presentation on the first morning of the videos he has made with Saul Schleimer using a spherical camera. By applying well-known geometrical transformations to carefully contrived scenes they have created some stunning visual effects (Fig. 1).

Another memorable plenary session was Harri Varpanen (and friends) who took juggling to new heights. The mathematics of juggling has received a lot of attention in the last ten years or so (Varpanen 2014), and many new patterns have been discovered/invented, but the creativity and virtuosity displayed in this presentation were particularly impressive.

It is not surprising that patterns from the Islamic world are an enduring topic of the conference. A regular contributor, Jean-Marc Castera, who has also contributed to the Nexus Network Journal (2016), considered the design of pentagonal Persian patterns from his usual point of view of individual shapes of tiles (all of which have traditional names) rather than the more common one of geometrical construction (generally inspired by the Top Kapi scroll). Ron Asherov took an even more controversial view of a particular Mamluk pattern that led to some disagreements about details of its construction.

There was time before David Chappell's short talk to discuss his theme of the nature of generative art. What constitutes mathematical art, and its validity as art, are natural questions at Bridges, and Chappell's paper provides some starting points that might lead to more significant insights than the usual, rather sterile commentary.

The art exhibition is an important feature of Bridges that has also continued to grow from very small beginnings. In the past few years there has been a competition where people have voted for their favourite pieces, and this year the best in show was a 3D object by Hans Kuiper and Walt van Ballegooijen that showed three

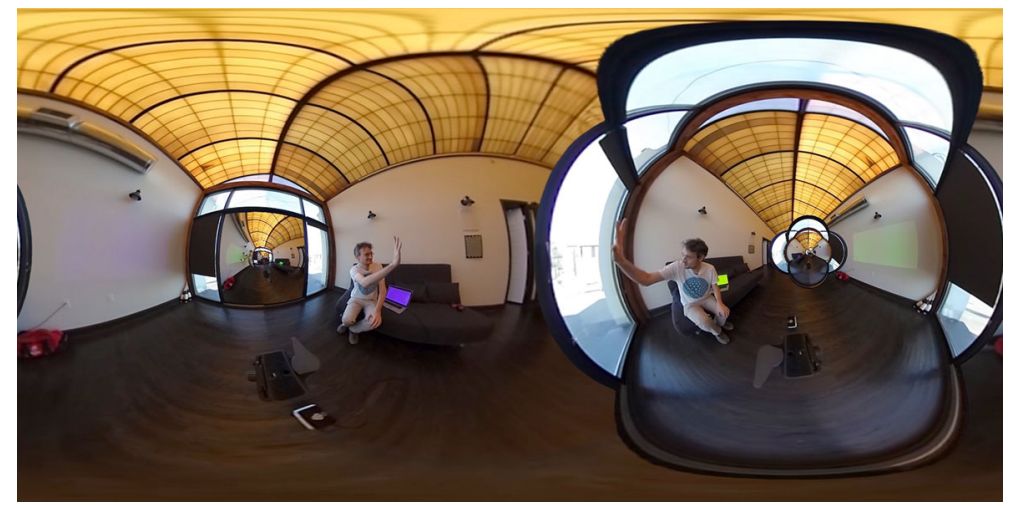

Fig. 1 A visual effect using transformed images from a spherical camera 
different images depending on the viewing direction (Fig. 2). It was a development of an idea from Hofstadter's book Gödel, Escher, Bach (1979) and the images were portraits of these three creative minds. The object was presented in a box designed with mirrors so that all three views could be seen simultaneously. The other prizes were won by Kiyoko Urata's Temari pieces (selected by Koji Miyazaki), Albrecht Wintterlin's model of a finite projective plane, and Judy Holdener's 2D piece incorporating images of some of those aspects of mathematics that are particularly important to her.

Different aspects of textile design have become more frequent as Bridges submissions, and an interesting one this year was Nithikul Nimkulrat's new knotted fabric structure (Fig. 3), described in the proceedings and included in the art exhibition. There has been some recent work on the influence of textile design in architecture (Spuybroek 2011), and it would be good to see more examples submitted to Bridges.

There are few conferences where participants from different disciplines are likely to engage with each other, but one of the principle aims of Bridges is to stimulate such meetings, and the art exhibition provides one of the best opportunities to achieve this aim. For example, Martin Levin's model, A Cube Inscribed on the Faces of a Dodecahedron, held special interest for me since many years ago I had investigated a related polyhedron (Ounsted 1978), so I kept going back to it to check if I understood it correctly. The piece next to it was Land of Plenty by R. Wayne Reynolds, who has little background in mathematics (Fig. 4). He was often explaining his work to people when I was there, and eventually we had a detailed discussion about creativity in mathematics and the visual arts. Such encounters are as important as the formally scheduled events, and are an essential aspect of the unique character of Bridges.


Fig. 2 Portraits of Gödel, Escher and Bach in a single object 


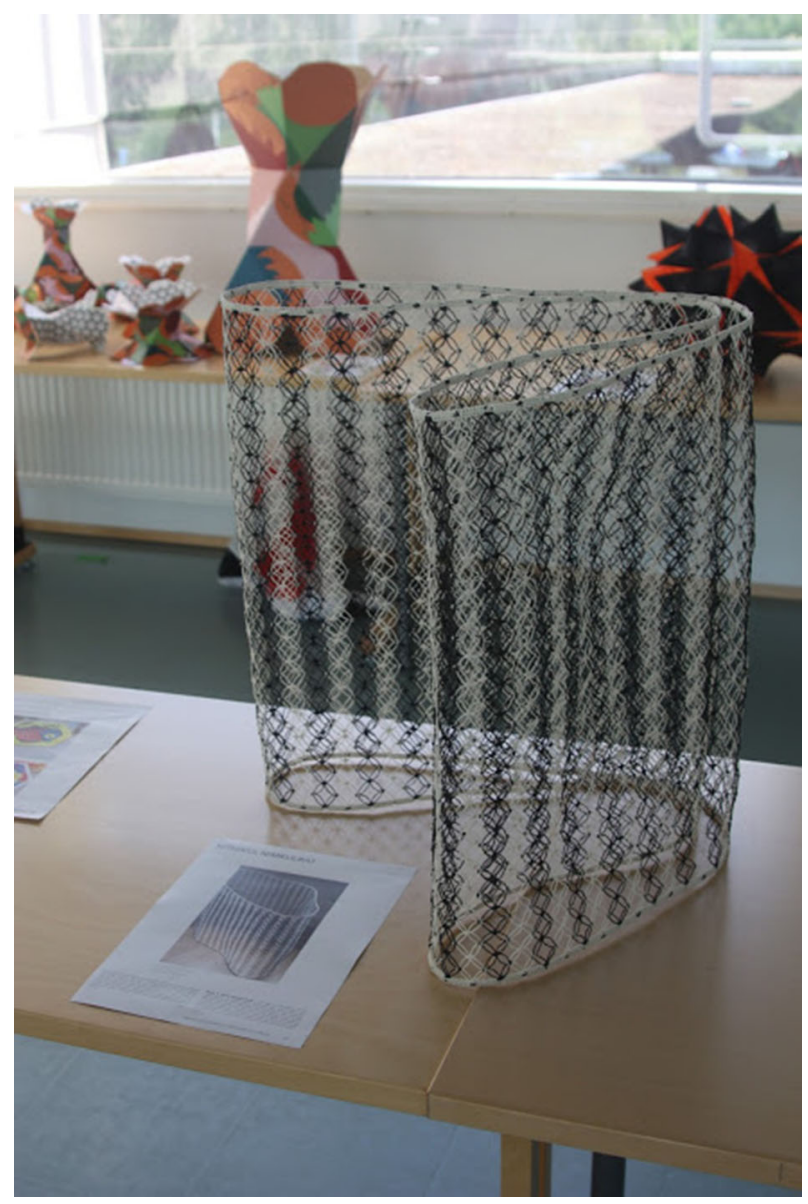

Fig. 3 A new knotted fabric structure


Fig. 4 A geometrical exhibit and the neighbouring art-work with its creator 
Sometimes there are other exhibitions open to the public mounted in connection with the conference, and this year there were two: an extensive collection of paper constructions, mainly polyhedral, by Rinus Roelofs at the Natural History Museum (Fig. 5), and a joint exhibition of work by two Hungarians: Lajos Szilassi and István Orosz (Fig. 6). Szilassi is famous for his discovery of a realisation of the torus with seven hexagonal faces with no intersections, and he was present to explain sculptures of this and many other tori with several hexagonal faces. Orosz could not be present, but there was a wide selection of his well-known graphical work incorporating anamorphosis, impossible images and optical illusions.

Corey Cerovsek was a regular contributor to Bridges in the early years, and his plenary session on Friday morning brought back many memories. After telling us how he did not like talking he proceeded to talk at some length before playing from one of J.S. Bach's violin sonatas, with commentary between movements. Formal Music Night usually consists of modern mathematically inspired music, but this year it came at the end of the excursion, with Corey and Paavali Jumppanen playing violin sonatas by Prokofiev and Debussy, finishing with Beethoven's Kreutzer sonata.

Saturday's excursion began with a visit to the Alvar Aalto Museum in Jyväskylä (http://www.alvaraalto.fi/) where conference participants were able to see some of his architectural models and drawings, plus examples of furniture and glassware that he designed. This was followed by a bus journey to the nearby town of Mänttä, with visits to three interesting museums, finishing with Corey's concert in the Club House. The excursion included a visit to the old church of Petäjävesi built in the middle of the eighteenth century. It is one of the few remaining wooden churches in Finland, most of the others having burnt down. The short guide leaflet states that its shape is based on that of Renaissance churches, by which it probably means cruciform. The construction seemed rather to reflect agricultural buildings, which is hardly surprising since it was produced by local craftsmen.

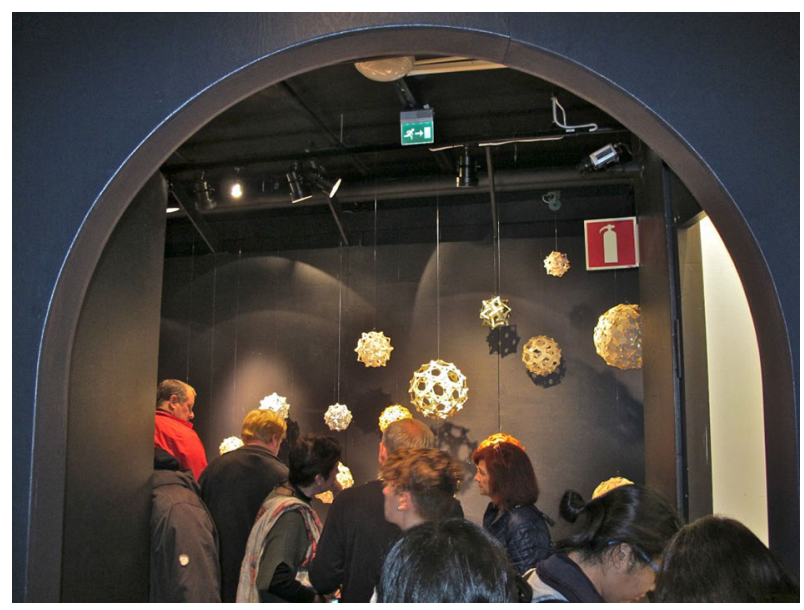

Fig. 5 Paper constructions by Rinus Roelofs 


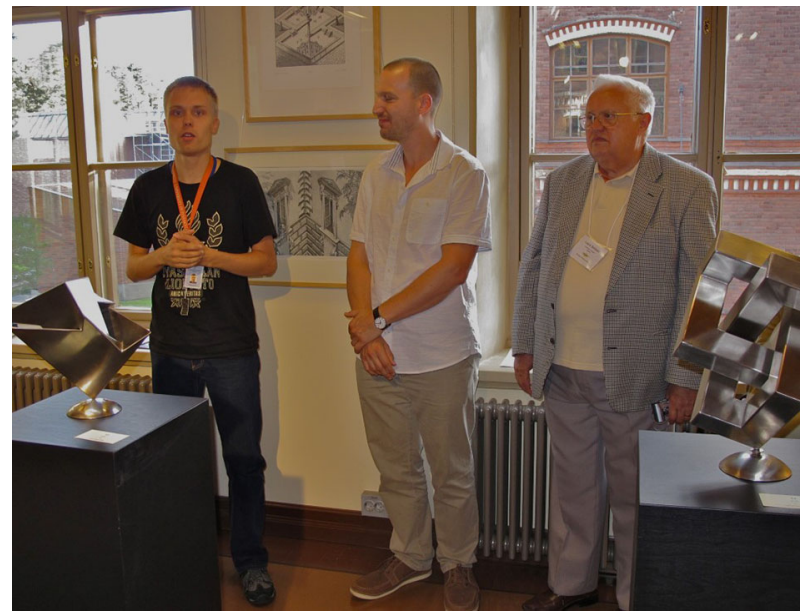

Fig. 6 Lajos Szilassi and some of his sculptures with prints by István Orosz in the background

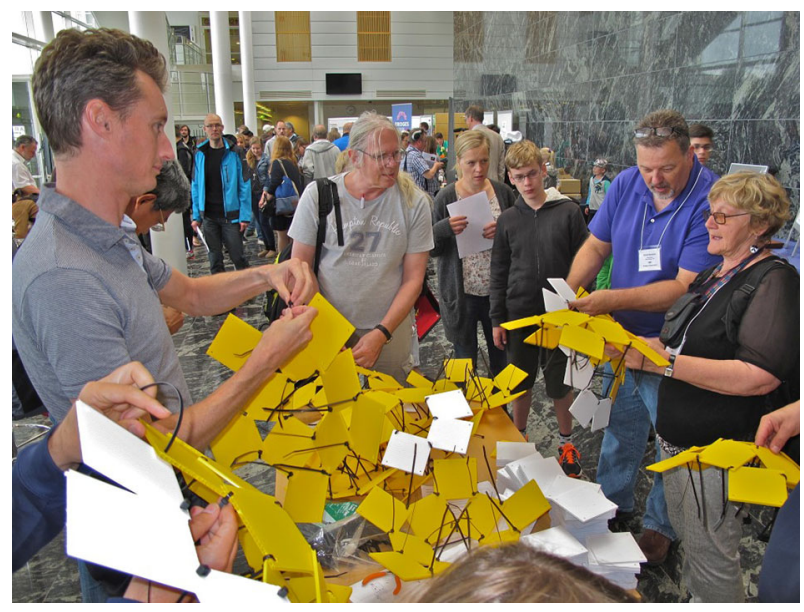

Fig. 7 Family day

Family Day, a feature of Bridges since 2006, is free and open to the public, and includes many hands-on activities based on mathematics for people of all ages. It serves to spread the conference ideas to a wider audience. This year it was part of a wider Public Day held on Friday that included most of the additional events, which are more usually spread out over the evenings of the conference. There were two showings of the Short Movie Festival that included a small part of Schleimer and Segerman's work with spherical cameras and a nice animation of normal mode vibrations of a circular membrane (Fig. 7).

A sad event commemorated at the conference was the death of Reza Sarhangi a few weeks earlier. Reza was the founder and driving force behind Bridges (Fenyvesi 2016). I was not at the first conference, but I remember one of his colleagues from 
Southwestern College telling me in Granada how nobody thought that people would come to a remote place like Winfield, Kansas, but Reza persisted, and eventually the college authorities agreed to host the conference. It was a success, and began to attract a widening circle of attendees. I first went to Bridges in 2000, and was very impressed by the quality of the presentations, the printed proceedings (always produced in advance making it easier to decide among parallel sessions), and above all, by the friendly atmosphere and feeling of cooperation in a community of interesting people with a wide diversity of backgrounds. That sense of community has continued, although these days conferences are attended by many more people (about 350 this year) and they are held in locations that generally lack the intimacy of Winfield. More than anything the sense of community is what makes Bridges special, and it owes much to Reza's support, commitment, and unfailing good humour through the years. He will be greatly missed.

Although we regret Reza's passing Bridges continues, and in 2017 the conference will take place in Waterloo, Canada, 27-31 July. I can think of no better way to spend a week next summer.

\section{References}

Castera, Jean-Marc. 2016. Persian Variations. Nexus Network Journal 18(1): 223-274.

Fenyvesi, Kristóf. 2016. Bridges: A World Community for Mathematical Art. The Mathematical Intelligencer 38(2): 35-45.

Hofstadter, Douglas. 1979. Gödel, Escher, Bach: an Eternal Golden Braid. New York: Basic Books, 1979.

Ounsted J. 1978. An Unfamiliar Dodecahedron. Mathematics Teaching 83: 46-7.

Spuybroek, L., ed. 2011. Textile Tectonics. Rotterdam: Nai.

Varpanen, H. 2014. Toss and Spin Juggling State Graphs. In: Bridges Seoul Conference Proceedings: 301-308.

Paul Gailiunas holds a degree in Natural Sciences from the University of Cambridge. He is interested in visual aspects of mathematics and mathematical aspects of the visual arts, and he has participated in every annual Bridges conference since 2000, as well as every triennial Symmetry Festival since 2003. As well as conference papers he has contributed to the Journal of Mathematics and the Arts, the International Journal of Mathematical Education in Science and Technology, Mathematics Teaching, and written several articles for and helped to edit Infinity, a short-lived magazine of recreational mathematics. His other interests include bookbinding, and he co-edited The Bookbinder, the journal of the Society of Bookbinders, from 2008 to 2012. He is currently chairman of The Literary and Philosophical Society of Newcastle upon Tyne. 